\title{
Research On The Marketing Innovation Of "Live + Short Video" In The Culture And Tourism Industry In We Media Era
}

\author{
Guo jun \\ ${ }^{1}$ Shandong Polytechnic College, Shandong, Jining, 272100
}

\begin{abstract}
With the development of Internet technology and the popularity of $5 \mathrm{G}$ technology in mobile terminals, we media has entered the era of "short video + live broadcast" from the era of graphics and text on mobile terminals. The number of users of "live video + short video" app platform has reached 888 million, accounting for $94.5 \%$ of the total Internet users in China. In 2020, the sales revenue of all kinds of flat broadcast e-commerce will reach trillion, and cultural and tourism enterprises pay more and more attention to live broadcast We should pay dividends for the development of tourism enterprises, and carry out publicity and marketing of tourism routes and products. Tiktok and Kwai platform are taken as examples to analyze the problems the problems existing in the promotion of "live + short video" by cultural tourism enterprises. At the same time, it puts forward its own views on how to carry out the marketing innovation of "live + short video" in the cultural tourism industry of tourism cities.
\end{abstract}

\section{The emergence and development of the We Media}

\subsection{The generation and characteristics of the concept of We Media}

The concept of "We Media" originated from the concept proposed by American scholars Schein Bowman and Chris Willis in 2003. The author points out that the monopoly position of information supply of traditional mainstream media will face challenges, and We Media experience will become "mainstream media in the future". We media refers to the public through the Internet platform, using point-to-point or point-to-point way to broadcast their own information or their own filtering processing content to other people. Compared with traditional communication methods such as TV, we media has the characteristics of interaction, group, individuality and communication. Its most prominent advantages are wide audience, faster information dissemination, diversified forms of communication and free from time and space restrictions.

\subsection{From the development stage and trend of We media}

Before 2005, the era of traditional media dominating the world was followed by the BBS forum, post bar, blog, micro-blog, official account and other media. Especially in 2009, Sina micro-blog launched the trend of social media self media, and entered a new revolution of traditional media. With the development of $4 \mathrm{G}$ and $5 \mathrm{~g}$ mobile Internet technology, the media has entered the stage of mobile short video and live broadcast.

Table 1. We Media Development Stage

\begin{tabular}{|c|c|c|c|}
\hline $\begin{array}{c}\text { We media } \\
\text { developm } \\
\text { ent stage }\end{array}$ & Type & $\begin{array}{c}\text { Generation } \\
\text { time }\end{array}$ & $\begin{array}{c}\text { Typical } \\
\text { representative }\end{array}$ \\
\hline 1.0 Era & $\begin{array}{c}\text { The era of } \\
\text { network writers }\end{array}$ & $2003-2009$ & $\begin{array}{c}\text { BBS } \backslash \text { Blog } \backslash \text { Post } \\
\text { Bar }\end{array}$ \\
\hline 2.0 Era & $\begin{array}{c}\text { The era of } \\
\text { Mobile } \\
\text { graphic\&text }\end{array}$ & $2010-2015$ & $\begin{array}{c}\text { Weibo/ } \\
\text { WeChat official } \\
\text { account }\end{array}$ \\
\hline 3.0 Era & $\begin{array}{c}\text { The era of Live } \\
\text { and short video }\end{array}$ & $\begin{array}{c}2015 \text { to } \\
\text { present }\end{array}$ & $\begin{array}{c}\text { Tiktok/Kwai/w } \\
\text { esee }\end{array}$ \\
\hline
\end{tabular}

\section{The influence of the development of "live + short video" platform on tourism consumption}

\subsection{Properties of live + short video}

The app platform "live + short video" has both social and media attributes, which shows more abundant and more advantages in the way of communication content and audience interaction. On the one hand, the app platform "live + short video" has powerful social functions, which can import more traffic through social sharing, and form social links and communities in various forms of interaction. On the other hand, the content conveyed by the app platform "live + short video" is more real and rich. From the perspective of users, the production content and communication threshold are reduced through the mobile video clip tool. For enterprises or 
individuals, the lower threshold to enter live broadcast is actually to embed products and services into short video and live content. It shows the advantages of "live + short video" traffic and content.

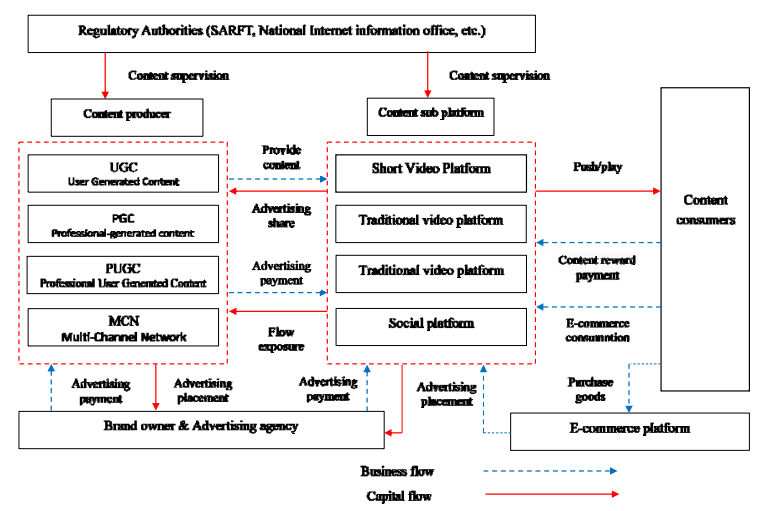

Fig.1.Industry chain structure of short video industry

\subsection{The influence of the era of "live + short video" on Tourism}

Short video and live broadcast make tourism scene, breaking the traditional single flat publicity, not only enhance the interaction with users, but also bring the real experience of the user in the real world. Under the influence of the new crown virus epidemic, the live tourism has become the main channel of tourism distribution. And the main force of tourism consumption has become the post- 85 and post-90s, they pay more attention to the network hot spots, and are also the main audience of online broadcast. "Live + short video" has changed essentially to the user experience or the scenic area.

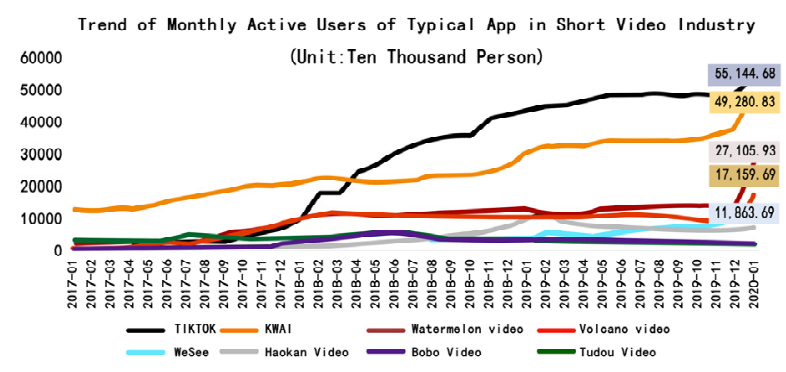

Fig. 2. Trend of Monthly Active Users of Typical App in Short Video Industry (Unit: Ten Thousand Person)

According to the data of China Internet Information Center, by june2020, the number of live e-commerce users in China has reached 309million, accounting for $32.9 \%$ of the total Internet users. In 2020, the market scale of live e-commerce will exceed trillion, with a penetration rate of $8.6 \%$, and live e-commerce will enter a high-speed development period. Especially in the context of the epidemic, for major tourist destinations and tourism enterprises, they began to adopt the form of seeking to sign up with or hire stars to live broadcast, and create a powerful tool for tourism marketing promotion by using the mode of "net red + tourism + live broadcast". According to statistics, the mode of "Internet star + tourism + live broadcast" has achieved good promotion effect in the domestic tourism enterprises and tourism platform's live tourism programs and tourism live variety.

Table 2. Comparison of short video platform operation data $(06 / 2020)$

\begin{tabular}{|c|c|c|c|c|c|}
\hline $\begin{array}{l}\text { parameter } \\
\end{array}$ & Tiktok short video & Tiktol Speed version & Tiktok Voltenan version & Kwai & Krai Speed rersion \\
\hline MAU(ten thousand) & 51,336 & 8,840 & 7,853 & 42,975 & 12,118 \\
\hline yoy & $5.6 \%$ & & $-25.9 \%$ & $26.2 \%$ & $15050 \%$ \\
\hline Datahu & $57.5 \%$ & 44.4\% & $36.8 \%$ & $50.0 \%$ & $57.9 \%$ \\
\hline Monthly average duration(min) & $1,569.5$ & 994.3 & 852.0 & $1,162.6$ & $1,389.8$ \\
\hline yoy & $44.9 \%$ & & $5.5 \%$ & $2.2 \%$ & $264.4 \%$ \\
\hline $\begin{array}{l}\text { Per capita duration of a single } \\
\text { day(min)20/05 }\end{array}$ & 93 & 54 & 77 & 86 & 80 \\
\hline soy & $38.5 \%$ & 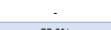 & $16.5 \%$ & $57.5 \%$ & $48.2 \%$ \\
\hline Active users 7 -day retention rate & $87.2 \%$ & $77.8 \%$ & $65.5 \%$ & $82.9 \%$ & $83 \%$ \\
\hline Unloading rate & $6.0 \%$ & $23.0 \%$ & $10.3 \%$ & $8.1 \%$ & $13.7 \%$ \\
\hline
\end{tabular}

\section{Problems in the current publicity of "live + short video" platform in cultural tourism scenic spots}

After investigating Kwai and Tiktok APP platform, there are several problems.

\subsection{Most scenic spots do not open official accounts on the "live + short video" platform}

Taking Jining City of Shandong Province as an example, Kwai and the Tiktok platform research found that are currently only officially opened on official accounts, including Liangshan scenic area, Nishan Holy Land, Niu Lou Huahai colored field, Qufu three hole scenic spot, Jining Wen brigade group and other enterprises in Tiktok, Kwai live and short videos. The number of fans accounts for Tiktok is over 100000 , only the Liangshan scenic spot, the NiShan holyland, and Niu Lou scenic spot, Liangshan is the largest number of fans, has exceeded 200 thousand people, and the only 5A scenic spot in the tourist city has more than 7000 fans with official account. Tiktok and Kwai account are not widely available in other scenic spots and enterprises. Most of the enterprises still rely on offline sales channels to promote their own tourism routes and products.

\subsection{The quality of short video is not high, and the number of praise is not much}

Kwai and Tiktok platform background data survey found that the major tourist attractions enterprises in the sound and fast platform works are not high, such as Qufu three hole scenic area of the total number of about 320 video, the number of points is generally around 32 thousand, the average number of works in praise less than 100 . Through the platform investigation, it is found that the cultural tourism enterprises are using the platform of "live + short video" to publicize, and use the traditional media advertising style. It shows that the cultural tourism enterprises in tourism cities do not attach importance to the platform publicity of "short video + live broadcast" in scenic spots, and the means are single, and the innovation of high-quality UGC (User Generated Content) is not encouraged. 


\subsection{Failed to establish its own culture and travel network red flow brand}

At present, the number of licensed tour guides in China reaches 800000 , and it is not much to become the red flow brand of scenic spots network as a tour guide. For fans, 7 million, Tiktok, Terracotta Army ice, micro-blog red man, Heisenberg, and Hangzhou private custom guide $\mathrm{Hu}$ Nana, after all, the proportion of tourism employees is very small. Like the fans of Datang night city, Miss Pikachen, a 2.2 million fans Miss tumbler, has become a key propaganda point in the city. So for most of the cultural and tourism enterprises, how to build their own culture and tourism network red flow brand is a new research topic.

\subsection{Lack of talents to publicize on the platform of "live + short video"}

At present, the leaders or marketing leaders of cultural tourism enterprises do not understand the Internet or the network who understand tourism. There are only some simple supporting facilities in the marketing of new media on the network, which is equivalent to the extension of internal publicity; there is a serious lack of people who are proficient in the "live + short video" publicity, such as file planning, video shooting, live broadcast, KOL network red group, etc., and there are video publicity in the past The mode of the film is promoted by short video, which can not transform the hot spot drainage of the network, let alone the realization of the problem.

\subsection{The government departments pay less attention to the promotion of "live + short video" platform}

The government departments in charge of tourism industry often play an important role in the publicity of tourism city image. They can establish the medium and long-term image of tourism destination city, enhance the attraction of tourism destination and realize the strategic goal of tourism industry development. According to the survey, although the government departments in charge of the culture and tourism industry in most tourism cities begin to attach importance to the promotion and marketing of new media, the investment and support on the platform of "live + short video" are not enough. In April 2018, Tiktok announced its cooperation with the Xi'an Municipal Development Commission. Based on Tiktok full range of products, it will promote the cultural tourism resources of Xi'an through the promotion of cultural cities, the customization of city theme challenges, the deep experience of Tiktok master, and the urban video of Tiktok.

\section{Marketing innovation strategy of "live + short video" in cultural tourism enterprises}

The Internet is really a world of short video and live broadcast. How to seize two core indicators of traffic and users, and it will be an important opportunity for tourism city to expand and strengthen the cultural and tourism industry by making good use of the "live + short video" development dividend.

\subsection{Strengthen the official account operation of "live + short video" platform}

Tiktok and government departments and enterprises should actively open official accounts from the media platform, strengthen account management and operation, establish a red brand of tourist city cultural tourism flow network. and encourage employees of cultural tourism enterprises to actively open new media accounts for people, forming media pools and media pools.

\subsection{Pay attention to the training of "live + short video" platform skills and methods for employees.}

From the Kwai tiktok government and enterprise two levels, the government departments of the government should take special training funds to train new media training for the industry management staff and top management of local tourism enterprises. For the enterprises of cultural tourism, enterprises should actively promote the algorithm recommendation, traffic distribution logic of learning and shaking, short hand video platform, and Short video shooting technology, video copywriting planning, video editing and other technologies, to create their own traffic network red brand.

\subsection{Tell the cultural stories of tourist cities and promote the high quality production of UGC (User Generated Content) platform of "live + short video".}

The platform of "short video + live broadcast" relies on the rich special effects and massive "divine music" developed to produce works with strong rhythm and magic, which makes the audience feel cool, dazzling and fashionable.

Tiktok and Kwai Tai platform, especially the integration of technology elements and artistic elements with the scene of Wen, makes the video very artistic, innovative and feel of the scene. More conducive to create a unique, multi fusion, interesting cultural tourism video content.

so the major tourism enterprises in tourism city should actively play the advantage of the social media platform of Tiktok and Kwai, and cooperate with colleges and universities to encourage more young people to experience their Tiktok products and services in the tourist city, and produce high-quality grass and 
short videos with their products, and put them into the shaking and fast platform, to enhance the heat of the scenic spots and form a hot spot of the network.

\subsection{The paper uses the user portrait and group difference of tourism consumer market facing the platform of "live + short video", cultivate KOL (Key Opinion Leader) in the vertical category of cultural tourism in tourism cities, improve the realization ability of e-commerce of "short video + live broadcast".}

Tourism cities have a large group of tour guides. With the brand effect of "gold guide" and "Star Tour Guide", we will play KOL in the vertical category of cultural tourism in tourism cities, so that the tourism practitioners will become the spokesperson of cultural and tourism industry in tourism cities. By creating the red label of KOL network, the tourism cities will create accurate marketing capabilities in different consumer groups, and bring goods with goods through live broadcast and short video grass planting, Improve the realization capacity of KOL e-commerce.

\subsection{The competent government departments attach importance to the official cooperation with MCN agencies and the platform of "live + short video", develop the "live + short video" products based on tourism city cultural and tourism products, and accurately launch tourism advertising.}

In the context of cultural tourism marketing, including government, platform operators, cultural tourism enterprises, online Red hosts and audience users stakeholders, can meet their own needs and create value. The audience users create traffic in the process of watching videos and participating in interaction free; the online Red anchor obtains certain subsidies for highquality content given by the "live + short video" platform in providing video content and attracting traffic, forming a "Internet red big curr" or KOL with millions of fans and specific labels, which is more conducive to the choice of traffic anchor and the destination of culture and tourism, so as to make marketing promotion more convenient With precision, the volume of tourists and tourism income significantly increased to realize the realization of flow,

\section{Conclusion}

In the "online" communication under 5G background, "visualization and fragmentation" will be a new trend of tourism promotion in the future. In the process of Intelligent Tourism and big data platform construction, the competent departments of tourism and culture and tourism government and cultural tourism enterprises in tourism cities should pay attention to the construction of "live + short video" quality content and the construction of red flow scenic spots, and encourage "the mining of cultural and tourism stories in scenic spots, living in the ground" The refined way and other high quality UGC content are produced, so the cultural tourism scenic spots in tourist cities will be more popular with tourists.

\section{Author}

1The author: Guo Jun (1974 -), male, from Jining, Shandong Province, associate professor, School of culture, tourism and art, Shandong Polytechnic College, research direction: tourism e-commerce and informatization.

\section{Acknowledgments}

Project source: Jining social science planning project "Jining cultural tourism" live + short video "marketing innovation research from the perspective of media" 2020

\section{Reference}

1.The 46th statistical report on the development of China's Internet, China Internet Information Center (CNNIC), September (2020).

2. Wang Guanghui, Chenjianyu, Wuhongyan, Optimization analysis of the publicity mode of online broadcast in tourist attractions, Economic Research Guide, 20th issue (2019)

3. Li Chenfang, Based on the characteristics of short video platform tourism destination marketing strategy: take Tiktok App as an example, Modern Communication, 9th issue (2019).

4. Lianghuihuang, Zouyongxin, Analysis of the promotion strategy of online tourism products online live broadcast based on 4R Theory, Journal of Hunan University of Finance and Economics, October 2017

5. Wang Qiong, "Tourism + live broadcast" new tourism marketing model research, Journal of Hebei Tourism Vocational College 2nd issue, August (2020)

6. Deng Zhaoming, Xiang wenya Li Xu,inspiration of Tiktok short video to tourism marketing, China Tourism News, May 22, 2018, China Tourism News

7.Mob Research Institute: 2020 China short video industry insight Report, August (2020).

8. Rosie, Short Video Competition Analysis Report: Tiktok vs Kwai, December (2020) 